\title{
Evaluation of the body mass index in breast cancer prognosis in a cohort of small-stature overweight patients: multi-center study in China
}

\author{
Xin Tan ${ }^{1 \#}$, Danju Huang ${ }^{2 \#}$, Fan Zhang ${ }^{3,4 \#}$, Yingzhu Zhao ${ }^{5,6}$, Mingjian Tan ${ }^{1}$, Hongwan Li ${ }^{1}$, Hengyu Zhang ${ }^{1}$, \\ Ke Wang ${ }^{1}$, Huimeng $\mathrm{Li}^{1}$, Dequan Liu ${ }^{1}$, Rong Guo ${ }^{1}$, Shicong Tang ${ }^{1,4}$ \\ ${ }^{1}$ Department of Breast Surgery, the Third Affiliated Hospital of Kunming Medical University, Yunnan Cancer Hospital, Kunming, China; \\ ${ }^{2}$ Department of Radiotherapy, the Third Affiliated Hospital of Kunming Medical University, Yunnan Cancer Hospital, Kunming, China; \\ ${ }^{3}$ Department of Thyroid Breast and Vascular Surgery, the First Affiliated Hospital of Xinxiang Medical University, Xinxiang, China; ${ }^{4}$ Department of \\ Breast Surgery, Affiliated Tumor Hospital of Guangxi Medical University, Nanning, China; ${ }^{5}$ Department of Hepatobiliary and Pancreatic Surgery, \\ The People's Hospital of Guangxi Zhuang Autonomous Region, Nanning, China; ${ }^{6}$ Breast and Thyroid surgery, The People's Hospital of Guangxi \\ Zhuang Autonomous Region, Nanning, China \\ Contributions: (I) Conception and design: R Guo; (II) Administrative support: D Liu, D Huang, F Zhang; (III) Provision of study materials or patients: \\ Y Zhao, H Li, M Tan, H Zhang; (IV) Collection and assembly of data: X Tan; (V) Data analysis and interpretation: X Tan, S Tang; (VI) Manuscript \\ writing: All authors; (VII) Final approval of manuscript: All authors. \\ \#These authors contributed equally to this work. \\ Correspondence to: Dequan Liu; Rong Guo; Shicong Tang. Department of Breast Surgery, the Third Affiliated Hospital of Kunming Medical \\ University, Yunnan Cancer Hospital, Kunming, China. Email: liu_dequan2018@126.com; guorong2320@126.com; tang_shicong@126.com.
}

Backgroundk Overweight and obesity have become a major health issue in the past 30 years. Several studies have already shown that obesity is significantly associated with a higher risk of developing breast cancer. However, few studies have assessed the prognostic value of the body mass index (BMI) in Asian populations. The purpose of this study was to retrospectively analyze the impact of BMI on the prognosis of breast cancer in overweight, under $160 \mathrm{~cm}$ tall patients from southern China.

Methods: We retrospectively analyzed data from 525 breast cancer patients diagnosed between 2003 to 2010 in a multi-center of China. After applying the exclusion criteria, 315 patients with complete data were retained. Their clinical and pathological characteristics were compared using the chi-square test. Survival analysis was performed with the Kaplan-Meier method. Univariate and multivariate analyses were performed using Cox regression to calculate hormone receptor status, HER-2 status, lymph node status, age, BMI and tumor size hazard ratio (HR), and 95\% confidence intervals (95\% CI).

Results: There was a strong correlation between $\mathrm{BMI}$ and age in the baseline feature analysis $(\mathrm{P}=0.001)$. After grouping the patients according to the molecular type of cancer, we found that in Luminal A and B, the $\mathrm{BMI}$ was related to age $(\mathrm{P}=0.002, \mathrm{P}=0.010)$. The disease-free survival (DFS) and overall survival (OS) of patients with different BMI were not significantly different. This conclusion was also reached by pairwise comparison of subgroups. There was no significant difference in recurrence in patients from different BMI groups. We did not find a critical weight threshold associated with higher risk of recurrence. There were no statistically significant differences in treatment among the three BMI groups of overweight patients.

Conclusions: We found that the BMI of Chinese breast cancer patients is related to age but not prognosis.

Keywords! Breast cancer; obesity; body mass index (BMI); disease-free survival (DFS); overall survival (OS)

Submitted May 07, 2020. Accepted for publication Sep 24, 2020.

doi: $10.21037 /$ gs-20-488

View this article at: http://dx.doi.org/10.21037/gs-20-488 


\section{Introduction}

Breast cancer is the most common malignant tumor and is one of the leading causes of cancer-related deaths in women $(1,2)$. With earlier detection and the increased number and improvement of treatment methods, the prognosis of breast cancer has been greatly improved (3). Yet the patients still face risks of recurrence and metastasis, and more predictive factors would help evaluate the prognosis and improve clinicians' management of high-risk patients. Overweight and obesity have become a serious health issue in the past 30 years. Since 1975, obesity has tripled globally. Obesity is a major risk factor for cardiovascular diseases, diabetes, musculoskeletal diseases, and numerous cancers, including endometrial, breast, gallbladder, liver, ovarian, prostate, kidney, and colon cancers (4-11). Obesity may also be a risk factor affecting tumor incidence and prognosis. In Sweden, a large case-control study reported in 2019 enrolling 14,766 twins tested whether being overweight [body mass index (BMI) $\geq 25$ ] is associated with higher risk of advanced cancer. The analysis showed that overweight is associated with increased risk of advanced colon, liver, and uterine cancers (12). In contrast, Yang and colleagues reported that overweight (BMI $\geq 25 \mathrm{~kg} / \mathrm{m}^{2}$ ) is inversely correlated with the incidence of lung cancer, indicating that overweight and obesity are protective factors against lung cancer (13). A recent report showed that obesity is an independent risk factor for lung cancer and that there is a positive correlation between obesity and lung adenocarcinoma (14). Schlesinger et al. reported that overweight rectal cancer survivors have a reduced mortality rate (15). There have also been many epidemiological studies confirming the role of obesity in breast cancer, and several studies have consistently shown a link between obesity and postmenopausal breast cancer (16-18).

Obesity is significantly associated with breast cancer recurrence, but higher BMI is not associated with higher overall mortality. Furthermore, in older women, BMI is inversely proportional to overall mortality (19). However, Berclaz et al. reached different conclusions. They reported that high BMI significantly affects overall survival (OS) but has no significant effect on disease-free survival (DFS) (20). At the same time, research by Fontanella $e t$ al. showed that the average DFS and OS of obese patients was significantly shortened compared with healthy weight patients (21). A meta-analysis of 82 studies in the United States examined the relationship between BMI and mortality and found that the risk of breast cancer-specific mortality (BCSM) was $35 \%$ higher in women who were obese $(\mathrm{BMI}>30)$ before diagnosis, compared with women with normal BMI (18.5-25) (22). Later, a study by Vernaci et al. confirmed the negative impact of obesity on breast cancer prognosis. High $\mathrm{BMI}$ was associated with a 10 -year relapse rate after diagnosis, a second primary tumor, and increased mortality (23). Sun et al. reported that the 5-year DFS and OS of overweight and obese patients are reduced, and overweight and obesity are independent predictors of increased risk of breast cancer recurrence and death (24).

To date, most studies addressing the link between breast cancer and BMI have targeted Western populations. Asian populations have not been widely studied. Considering that Asian women usually have a lower BMI than Western women, we sought to investigated the effect of BMI on breast cancer prognosis. An earlier study in Japan showed that both higher and lower BMI are associated with increased risks of death, especially in premenopausal or hormone receptor-positive tumor patients (25). Subsequently, a large-scale clinical study based on the Japanese National Clinical Database-Breast Cancer Registry enrolled a total of 42,390 patients and further confirmed that obesity or underweight is associated with a higher risk of death for Japanese women with breast cancer (26). The latest research in South Korea showed that the effect of BMI on breast cancer varies depending on subtypes and hormone receptor involvements, as well as with different menopausal statuses (27).

In China, with the improvement of living standards and the westernization of lifestyles, the BMI of the population has increased, especially among breast cancer survivors (6). Although different studies in China have confirmed that underweight, overweight, and obesity have significant impacts on breast cancer prognosis $(28,29)$, the relationship between BMI and prognosis in a Chinese population of people with the specific overweight/under $160 \mathrm{~cm}$-tall stature has not been reported so far. To fill this gap, we studied the relationship between BMI and breast cancer prognosis in the overweight/under $160 \mathrm{~cm}$-tall population.

We present the following article in accordance with the STROBE guideline checklist (available at http://dx.doi. org/10.21037/gs-20-488).

\section{Methods}

\section{Patients and ethics}

Our study includes a retrospective analysis of the medical records of 315 female patients diagnosed with breast cancer between January 2003 and December 2010, retrieved from 


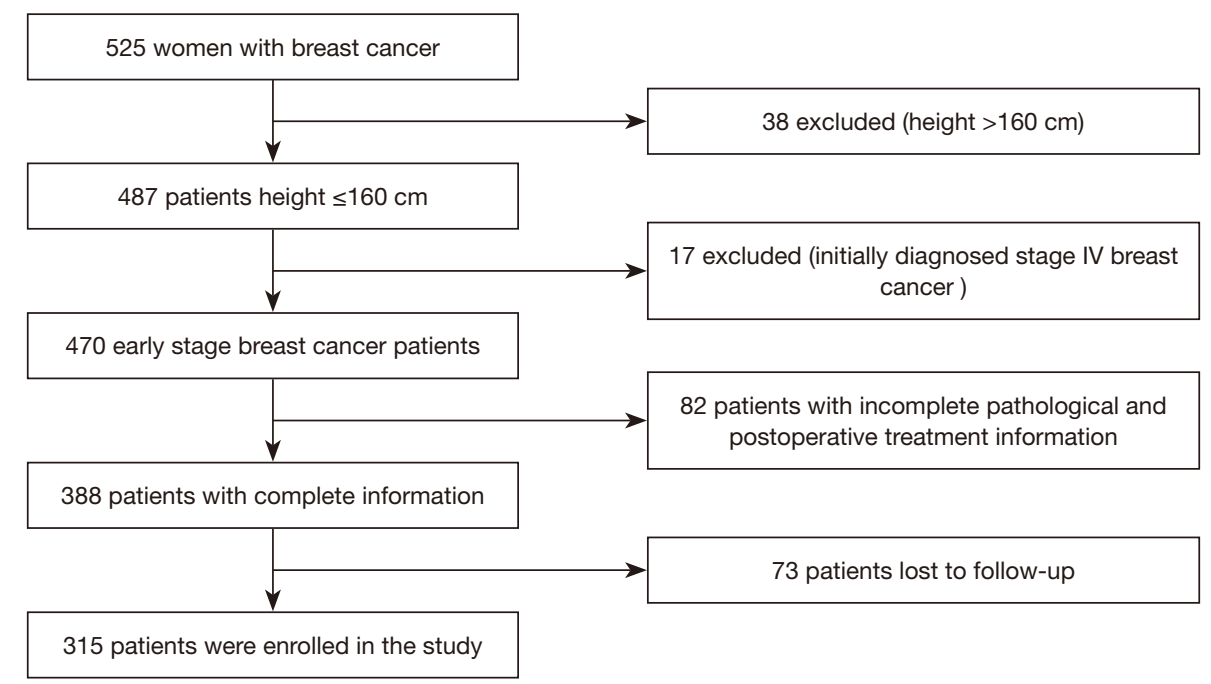

Figure 1 Among 525 newly diagnosed breast cancer patients, 38 patients height $>160 \mathrm{~cm}$ were excluded, 17 patients with newly diagnosed stage IV breast cancer were excluded, 82 patients with incomplete pathological information and incomplete postoperative treatment information, 73 patients who were lost to follow-up, and a total of 315 patients. Patients with complete follow-up records were enrolled in this study.

the prospective databases of the Third Affiliated Hospital of Kunming Medical University, the Affiliated Tumor Hospital of Guangxi Medical University, and the First Affiliated Hospital of Xinxiang Medical University. The study was conducted in accordance with the Declaration of Helsinki (as revised in 2013). The study was approved by People's committee of the Third Affiliated Hospital of Kunming Medical University (No. QT202001), the Affiliated Tumor Hospital of Guangxi Medical University (No. LW2020058), and the First Affiliated Hospital of Xinxiang Medical University (No. 2020341) and informed consent was taken from all the patients. All patients with pathological diagnosis of invasive cancer were included. Patients over $160 \mathrm{~cm}$ in height or with a previous history of breast cancer, stage IV breast cancer, or bilateral breast cancer were excluded. Clinical, pathological, and treatment information was collected for all patients. Local recurrence (LR) and distant recurrence (DR) events were recorded. Clinicopathological and therapeutic variables were compared based on patients' BMI. The research plan was approved by the People's Committee of the Third Affiliated Hospital of Kunming Medical University, the Affiliated Tumor Hospital of Guangxi Medical University, and the First Affiliated Hospital of Xinxiang Medical University.

This study includes patients who were diagnosed with breast cancer between January 2003 and December 2010 at the Yunnan Cancer Hospital, the Guangxi Medical
University Affiliated Cancer Hospital, the People's Hospital of Guangxi Zhuang Autonomous Region, and the First Affiliated Hospital of Xinxiang Medical University. Among the 525 newly diagnosed breast cancer patients, we excluded 38 patients with a height $>160 \mathrm{~cm}, 17$ patients with newly diagnosed stage IV breast cancer, 82 patients with incomplete pathological or postoperative treatment information, and 73 patients lost to follow-up. In total, 315 patients with complete follow-up records were enrolled (Figure 1). Information on weight and height was recorded at the time of the initial diagnosis, and the BMI was calculated as weight $(\mathrm{kg})$ divided by height squared $\left(\mathrm{m}^{2}\right)$. The WHO standard (30) categories for obesity are as follows: normal for BMI between 18.5 and 24.9, overweight for BMI greater than 25, and obese for BMI above 30. Because Asian people are relatively smaller, it is not appropriate to use the world standard for obesity, and Asian standards for obesity have been defined. Furthermore, Chinese experts insist that although the Chinese are Asians, the upper limit of the normal range of the body mass index should be lower than the Asian standard. As a result, the BMI China Standard categories are as follows: thin for BMI $<18.5$; normal for BMI ranging between 18.5 and 23.9; overweight for BMI ranging between 24 and 26.9; obese for BMI ranging between 27 and 29.9; severely obese for BMI from 30 and above. As part of the pathological information, the hormone-receptor (HR) status of the patients' tumors 
was determined by immunohistochemistry (ISH). HR positivity was defined as $1 \%$ of tumor cells positively stained for estrogen and/or progesterone receptors. HER2 status was assessed by ISH and fluorescence in situ hybridization (FISH). HER2 was defined as positive for $(+++)$ ISH score and/or FISH amplification (31). Molecular typing followed the St Gallen International Expert Consensus (32). Followup time was not considered for inclusion of the patients. In the final cohort, less than $1 \%$ of the patients had follow-up data up to 12 years after diagnosis, and $98 \%$ of the patients had a follow-up time longer than 70 months after diagnosis.

All 315 enrolled patients underwent regular followup after surgery, chemotherapy, radiation, and endocrine therapy. Regular follow-up included a tumor marker test, ultrasonography examination, and chest $\mathrm{X}$-ray every 2-3 months in the first year after surgery, every 6 months in the following 5 years, or every 12 months at later times. Radiographs with a molybdenum target tube, breast MRI investigation, isotope bone scan, curettage, and general investigation by CT were carried out once a year (33). All events were recorded in the database. The follow-up for the study was performed in August 2016, and the median follow-up time was 70.7 months (9.1 to 156.9 months). Clinical and pathological information related to all cancer patients, information on antitumor treatments and the date of the last follow-up or death were monitored during the follow-up period.

\section{Statistical analysis}

Endpoint events were metastasis, death, and survival at the end of the follow-up period. Deaths were specific to breast cancer, and relapses included local (remaining breasts, chest wall, axillary and regional lymph nodes) and distant metastases (lung, liver, bone, brain, distant lymph nodes, pleura, etc.). The survival time of each patient was calculated from the date of the surgery until death, relapse, or end of follow-up.

Comparison of the clinical and pathological characteristics and of recurrence was carried out using the chi-square test. In histology, Fisher's exact test was carried out when the cell expectation was less than six. The KaplanMeier test was used for survival analysis, and the results were compared using a log-rank test. Cox regression was used for univariate and multivariate analyses to calculate hormonal receptor, HER-2, and lymph node status, age, $\mathrm{BMI}$, and tumor size hazard ratio, with a $95 \%$ confidence interval (95\% CI). All statistical analyses used SPSS 25.0
(Chicago, USA) and GraphPad Prism 6.0. A P value $<0.05$ was considered statistically significant.

\section{Results}

\section{Clinicopathological characteristics of patients and tumors}

We retrospectively analyzed the data from 525 breast cancer patients. According to exclusion criteria, 137 cases were eliminated from the study. Seventy-three patients were lost to follow-up. In total, 315 patients with complete data were included (Figure 1). First, patients were divided into five groups according to the BMI China Standard Index as follows: $\mathrm{BMI}<18.5 ; 18.5<\mathrm{BMI}<23.9 ; 24<\mathrm{BMI}<26.9$; $27<\mathrm{BMI}<29.9 ; \mathrm{BMI} \geq 30$. Table 1 summarizes the clinical and pathological characteristics of the enrolled 315 breast cancer patients. We analyzed five BMI subgroups for age, tumor size, lymph node status, ER status, PR status, HER-2 status, and molecular subtypes. The results showed a strong correlation between $\mathrm{BMI}$ and age $(\mathrm{P}=0.001)$, whereas there was no statistically significant correlation between $\mathrm{BMI}$ and tumor size $(\mathrm{P}=0.380)$, lymph node status $(\mathrm{P}=0.799)$, ER status $(\mathrm{P}=0.603)$, $\mathrm{PR}$ status $(\mathrm{P}=0.241)$, HER-2 status $(\mathrm{P}=0.116)$, or molecular subtype $(\mathrm{P}=0.547)$. Further, we compared these correlations according to the clinical baseline characteristics of the patients, described in Tables S1-S4. In Luminal A and $\mathrm{B}$, the $\mathrm{BMI}$ was correlated with age (with respectively, $\mathrm{P}=0.002$, and $\mathrm{P}=0.010$; Tables $\mathrm{S} 1, \mathrm{~S} 2$ ). Across the different groups formed according to characteristics, no other correlation was statistically significant.

\section{Prognosis in different BMI groups}

After comparing clinical and pathological characteristics, we studied the relationship between BMI and disease prognosis. We performed an OS analysis using the KaplanMeier method. The OS and DFS rates in different BMI groups were not statistically different $(\mathrm{P}=0.4493$, Figure $2 A$; $\mathrm{P}=0.5275$, Figure $2 B$ ). Using Cox regression analysis, we next assessed whether BMI was an independent factor affecting prognosis. Neither univariate nor multivariate analyses supported that BMI could be a prognosis predictor (Table 2). Univariate analysis showed that tumor size and lymph node status can be used as independent predictors of DFS and OS (DFS: tumor size, $\mathrm{P}<0.001$, lymph node status $\mathrm{P}<0.001$; OS: tumor size $\mathrm{P}<0.001$, lymph node status $\mathrm{P}<0.001$; Tables 2,3). Multivariate analysis confirmed that tumor size and lymph node status can be used as 
Table 1 Comparison of clinicopathological characteristics between 5 different BMI group

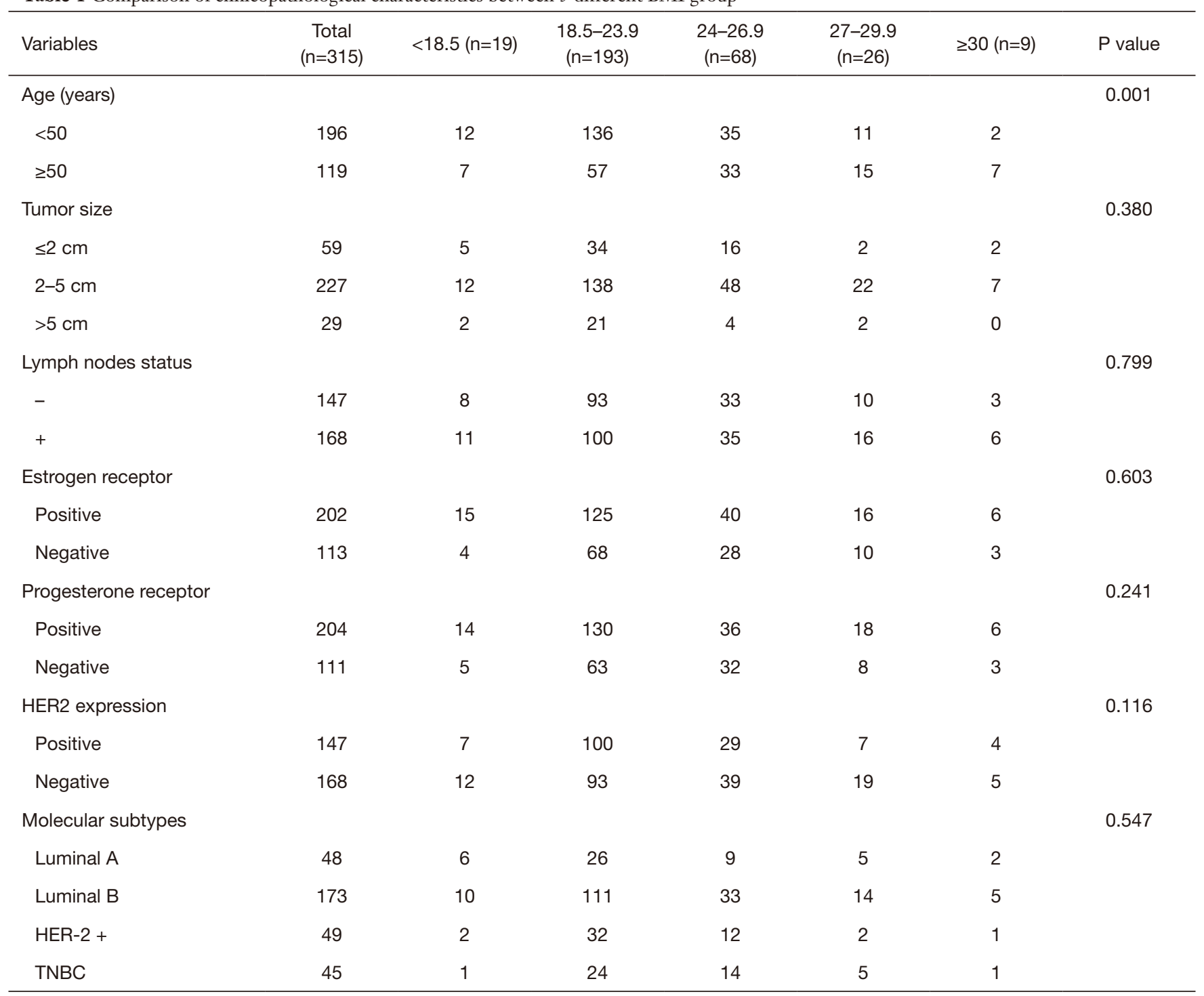

BMI, body mass index; HER2, human epidermal growth factor receptor-2; TNBC, triple negative breast cancer.

independent predictors of DFS and OS (DFS: tumor size $\mathrm{P}=0.012$, lymph node status $\mathrm{P}<0.001$; OS: tumor size $\mathrm{P}=0.020$, lymph node status $\mathrm{P}<0.001$; Tables 2,3).

\section{Correlation between recurrence and BMI in groups of patients with cancers of different molecular types}

We performed a BMI subgroup analysis within four groups of patients with breast cancers of different molecular types, i.e., Luminal A, Luminal B, Herb-2, and Triple negative. Within each molecular type, the number of patients without relapses in each BMI subgroup was greater than the number of patients who relapsed. Contingency in each molecular type group was not statistically significant (Luminal A: $\mathrm{P}=0.956$; Luminal $\mathrm{B}$ : $\mathrm{P}=0.534$; Herb-2: $\mathrm{P}=0.722$; Triple negative type: $\mathrm{P}=0.872$, Table 4 ). After studying the recurrence in BMI subgroups within different molecular type groups, patients were divided into 5 groups according to BMI. We wanted to study the recurrence in each BMI group independently of cancer molecular type. Within each BMI group, the number of patients with relapse was smaller than that of patients without relapse $(\mathrm{P}=0.510)$. Next, we calculated the recurrence rate according to the site of metastases. Twenty-four cases of recurrence occurred 
A

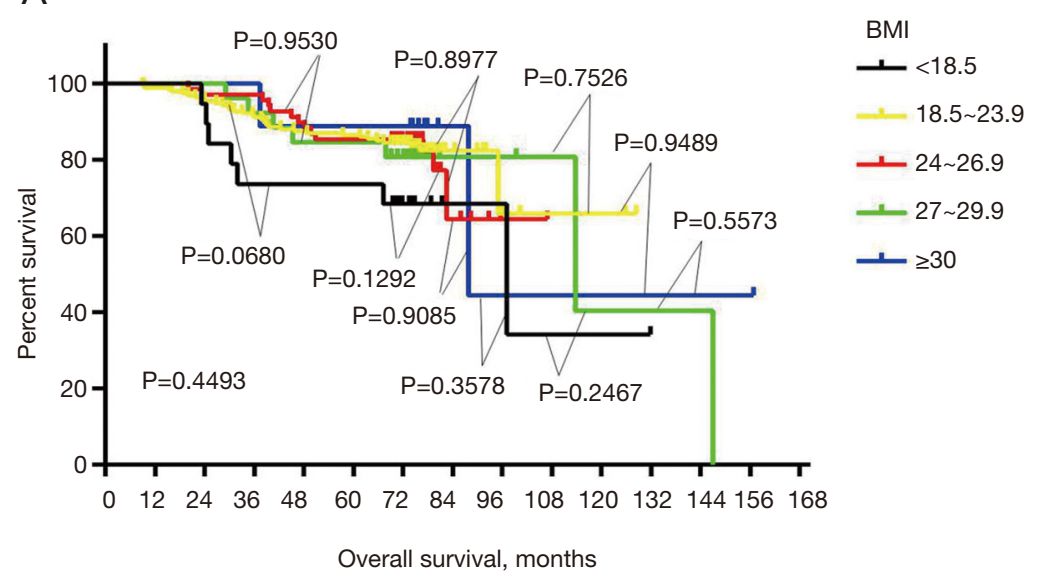

B

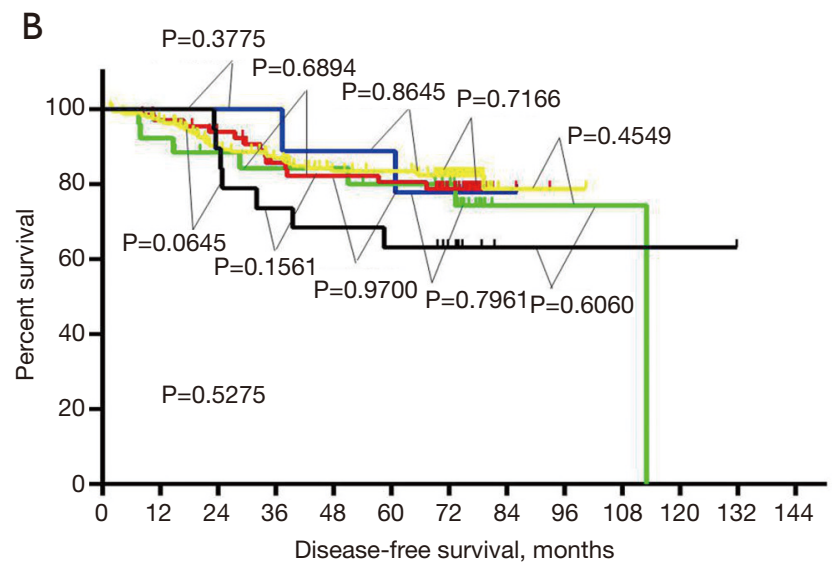

BMI

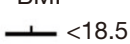

$+18.5 \sim 23.9$

$+24 \sim 26.9$

$+27 \sim 29.9$

$1 \geq 30$

Figure 2 We performed a Kaplan-Meier analysis for overall survival analysis. The disease-free survival rate and overall survival rate of the different BMI (Body Mass Index) groups were not statistically significant, and Pairwise comparisons between subgroups were also not statistically significant (A, $\mathrm{P}=0.4493 ; \mathrm{B}, \mathrm{P}=0.5275)$.

in liver, accounting for $26.4 \%$ of the total recurrence rate, 30 cases of bone metastasis accounted for $33.0 \%$ of the total recurrence rate, and 40 cases of lung metastasis accounted for $44.0 \%$ of the total recurrence rate. There were 8 cases of brain metastases, accounting for $8.8 \%$ of the total recurrence rate, and 44 cases of metastases occurring in other sites, accounting for $48.4 \%$ of the total recurrence rate (Table 5).

\section{Investigation of weight as a potential risk factor for breast cancer recurrence}

After studying the link between BMI and recurrence of breast cancer, we investigated a potential link between weight and recurrence in order to determine potential range of weight associated with increased risks. Fewer patients relapsed in all groups than those who did not $(\mathrm{P}=0.525)$. Then we counted the specific recurrence sites of patients, including 24 cases of liver metastasis, accounting for $26.4 \%$ of the total recurrence rate, 30 cases of bone metastasis, accounting for $33.0 \%$ of the total recurrence rate, 40 cases of lung metastasis, accounting for $44.0 \%$ of the entire recurrence rate, There were 8 cases of brain metastases, accounting for $8.8 \%$ of the total recurrence rate, and 44 cases of other site metastases, accounting for $48.4 \%$ of the entire recurrence rate (Table 6). After analyzing $5 \mathrm{BMI}$ groups and 5 weight groups, BMI was further divided as follows: normal and thin for $\mathrm{BMI} \leq 23.9$; overweighed for BMI between 24 and 26.9; obese for BMI between 27 and 29.9; severely obese for BMI $\geq 30$. We compared the recurrence in the normal and thin groups with that in the overweighed, obese, and severely obese groups. This 
Table 2 Cox regression analysis for disease free survival

\begin{tabular}{|c|c|c|c|c|c|c|}
\hline Variables & \multicolumn{3}{|c|}{ Univariate analysis } & \multicolumn{3}{|c|}{ Multivariate analysis } \\
\hline Age & 1.015 & $0.990-1.040$ & 0.240 & 1.016 & $0.990-1.043$ & 0.226 \\
\hline Tumor size & 2.698 & $1.646-4.422$ & $<0.001$ & 1.998 & $1.161-3.436$ & 0.012 \\
\hline Lymph node metastasis & 2.174 & $1.600-2.954$ & $<0.001$ & 1.991 & $1.437-2.757$ & $<0.001$ \\
\hline PR expression & 0.712 & $0.429-1.184$ & 0.188 & 0.904 & $0.453-1.806$ & 0.776 \\
\hline HER2 expression & 0.848 & $0.507-1.417$ & 0.529 & 0.693 & $0.405-1.187$ & 0.182 \\
\hline BMI & 0.994 & $0.918-1.076$ & 0.881 & 0.981 & $0.902-1.068$ & 0.659 \\
\hline
\end{tabular}

BMI, body mass index; ER, estrogen receptor; PR, progesterone receptor; HER2, human epidermal growth factor receptor-2.

Table 3 Cox regression analysis for overall survival

\begin{tabular}{|c|c|c|c|c|c|c|}
\hline Variables & \multicolumn{3}{|c|}{ Univariate analysis } & \multicolumn{3}{|c|}{ Multivariate analysis } \\
\hline Age & 1.018 & $0.993-1.044$ & 0.162 & 1.020 & $0.993-1.048$ & 0.142 \\
\hline Tumor size & 2.496 & $1.530-4.072$ & $<0.001$ & 1.841 & $1.102-3.074$ & 0.020 \\
\hline Lymph node metastasis & 2.209 & $1.622-3.010$ & $<0.001$ & 2.044 & $1.481-2.822$ & $<0.001$ \\
\hline PR expression & 0.747 & $0.449-1.242$ & 0.259 & 0.863 & $0.429-1.734$ & 0.678 \\
\hline HER2 expression & 0.826 & $0.495-1.377$ & 0.462 & 0.764 & $0.446-1.309$ & 0.327 \\
\hline BMI & 0.972 & $0.897-1.053$ & 0.484 & 0.948 & $0.871-1.031$ & 0.214 \\
\hline
\end{tabular}

BMI, body mass index; ER, estrogen receptor; PR, progesterone receptor; HER2, human epidermal growth factor receptor-2.

comparison indicated no significant differences between groups (overweighed versus normal and thin: $\mathrm{P}=0.271$; obesity versus normal and thin: $\mathrm{P}=0.406$; severely obese versus normal and thin: $\mathrm{P}=0.757$; Table 7).

\section{Comparison of therapies undergone by patients from the three overweight groups}

We next investigated if weight had an influence on the type of treatment undergone by the patients. There was no significant difference in treatments among the three overweight groups (Table 8). Breast-conserving surgery was performed in $10.3 \%$ of the overweight group, $3.8 \%$ of the breast-conserving surgeries were performed in the obese group, and no breast conservation surgery was performed in the severely obese group. However, there were no statistically significant differences between groups
$(\mathrm{P}=0.383)$. There were no significant differences among the three overweight groups in terms of chemotherapy $(\mathrm{P}=0.062)$, choice of chemotherapy regimen $(\mathrm{P}=0.216)$, or whether or not endocrine therapy was performed $(\mathrm{P}>0.999)$.

\section{Discussion}

Obesity per se has been classified as a disease state (34). It plays a critical role in several major diseases, including cardiovascular diseases, diabetes, and cancers (35). Whether in terms of risk or prevention, there is a growing body of evidence that obesity is associated with early onset of diseases related to cancers, recurrence, and an increased risk of cancer-related mortality. The impact of obesity on the prognosis of breast cancer has been widely reported in Western countries, and there is still controversy. The increased incidence of breast cancer associated with high 
Table 4 The recurrence between 5 different BMI group across different subtypes

\begin{tabular}{|c|c|c|c|c|c|c|c|c|c|}
\hline Subtype & Events & $\begin{array}{c}\text { Total } \\
(n=315)\end{array}$ & $\begin{array}{l}<18.5 \\
(n=19)\end{array}$ & $\begin{array}{c}18.5-23.9 \\
(n=193)\end{array}$ & $\begin{array}{c}24-26.9 \\
(n=68)\end{array}$ & $\begin{array}{c}27-29.9 \\
(n=26)\end{array}$ & $\geq 30(n=9)$ & $\begin{array}{c}\text { Chi-square } \\
\text { value }\end{array}$ & $P$ value \\
\hline Luminal A & Recurrence & 13 & 2 & 8 & 2 & 1 & 0 & 1.433 & 0.956 \\
\hline \multirow[t]{2}{*}{ Luminal B } & Recurrence & 49 & 1 & 30 & 11 & 5 & 2 & 2.973 & 0.534 \\
\hline & Non-recurrence & 122 & 9 & 80 & 21 & 9 & 3 & & \\
\hline $\begin{array}{l}\text { HER-2 } \\
\text { positive }\end{array}$ & Non-recurrence & 39 & 2 & 26 & 9 & 1 & 1 & & \\
\hline \multirow[t]{2}{*}{ TNBC } & Recurrence & 14 & 0 & 7 & 5 & 2 & 0 & 1.430 & 0.872 \\
\hline & Non-recurrence & 30 & 1 & 17 & 8 & 3 & 1 & & \\
\hline
\end{tabular}

BMI, body mass index; HER2, human epidermal growth factor receptor-2; TNBC, triple negative breast cancer.

Table 5 Recurrence of patients in different BMI

\begin{tabular}{|c|c|c|c|c|c|c|c|c|c|}
\hline BMI & $\begin{array}{c}\text { Total } \\
(n=315)\end{array}$ & $\begin{array}{l}\text { Recurrence } \\
\qquad(\mathrm{n}=91) \\
(28.9 \%)\end{array}$ & $\begin{array}{l}\text { Non- } \\
\text { recurrence } \\
(n=224) \\
(71.1 \%)\end{array}$ & $P$ value & $\begin{array}{c}\text { Recurrence } \\
\text { in liver } \\
(\mathrm{n}=24) \\
(26.4 \%)\end{array}$ & $\begin{array}{c}\text { Recurrence } \\
\text { in bone } \\
(n=30) \\
(33.0 \%)\end{array}$ & $\begin{array}{c}\text { Recurrence } \\
\text { in lung } \\
(\mathrm{n}=40) \\
(44.0 \%)\end{array}$ & $\begin{array}{c}\text { Recurrence } \\
\text { in brain }(\mathrm{n}=8) \\
(8.8 \%)\end{array}$ & $\begin{array}{c}\text { Recurrence } \\
\text { in other } \\
\text { sides }(n=44) \\
(48.4 \%)\end{array}$ \\
\hline$<18.5$ & 19 & $3(15.8 \%)$ & $16(84.2 \%)$ & 0.510 & 2 & 1 & 1 & 0 & 0 \\
\hline $18.5-23.9$ & 193 & 54 (28.0\%) & $139(72 \%)$ & & 12 & 18 & 23 & 6 & 25 \\
\hline $27-29.9$ & 26 & 10 (38.5\%) & $16(61.5 \%)$ & & 0 & 1 & 3 & 0 & 8 \\
\hline$\geq 30$ & 9 & 2 (22.2\%) & 7 (77.8\%) & & 0 & 1 & 1 & 0 & 0 \\
\hline
\end{tabular}

Table 6 Recurrence of patients in different weight

\begin{tabular}{|c|c|c|c|c|c|c|c|c|c|}
\hline Weigh (kg) & $\begin{array}{c}\text { Total } \\
(n=315)\end{array}$ & $\begin{array}{l}\text { Recurrence } \\
\qquad \begin{array}{c}(n=91) \\
(28.9 \%)\end{array}\end{array}$ & $\begin{array}{l}\text { Non- } \\
\text { recurrence } \\
(\mathrm{n}=224) \\
(71.1 \%)\end{array}$ & $P$ value & $\begin{array}{c}\text { Recurrence } \\
\text { in liver } \\
(\mathrm{n}=24) \\
(26.4 \%)\end{array}$ & $\begin{array}{c}\text { Recurrence } \\
\text { in bone } \\
(n=30) \\
(33.0 \%)\end{array}$ & $\begin{array}{c}\text { Recurrence } \\
\text { in lung } \\
(\mathrm{n}=40) \\
(44.0 \%)\end{array}$ & $\begin{array}{c}\text { Recurrence } \\
\text { in brain }(n=8) \\
(8.8 \%)\end{array}$ & $\begin{array}{c}\text { Recurrence } \\
\text { in other } \\
\text { sides }(n=44) \\
(48.4 \%)\end{array}$ \\
\hline$<40$ & 4 & $0(0 \%)$ & $4(100 \%)$ & 0.525 & 0 & 0 & 0 & 0 & 0 \\
\hline $40-49$ & 72 & 22 (30.6\%) & 50 (69.4\%) & & 7 & 10 & 10 & 2 & 9 \\
\hline $60-69$ & 81 & 28 (34.6\%) & $53(65.4 \%)$ & & 9 & 8 & 13 & 1 & 16 \\
\hline$\geq 70$ & 13 & $3(23.1 \%)$ & 10 (76.9\%) & & 1 & 2 & 1 & 0 & 1 \\
\hline
\end{tabular}

BMI may be related to metabolic and endocrine changes. Obesity may exacerbate estrogen production, lead to chronic subclinical inflammation, and increase circulating levels of proinflammatory proteins favoring cancer development (36). Bielawski's research showed that BMI is an independent predictor of survival, with overweight/ obese women being less prone to relapse (37). When we analyzed the BMI of patients belonging to different clinicopathological categories, we found a strong correlation between BMI and age. When we divided the patients into four subgroups according the molecular types of breast cancer affecting them, we found that within Luminal A and 
Table 7 Recurrence between chubby, obesity, severe obesity and normal, thin

\begin{tabular}{|c|c|c|c|c|c|c|c|c|}
\hline Stature & $\mathrm{BMI}$ & $\begin{array}{c}\text { Total } \\
(n=315)\end{array}$ & $\begin{array}{l}\text { Recurrence } \\
\qquad(n=91)\end{array}$ & $\begin{array}{c}\text { Non-recurrence } \\
(n=224)\end{array}$ & $\begin{array}{c}\text { Chi-square } \\
\text { value }\end{array}$ & $P$ value & $\begin{array}{c}\text { Hazard } \\
\text { ratio }\end{array}$ & $95 \% \mathrm{Cl}$ \\
\hline $\begin{array}{l}\text { Chubby vs. normal } \\
\text { and thin }\end{array}$ & $\leq 23.9$ & 212 & 57 & 155 & 1.214 & 0.271 & 0.719 & $0.400-1.294$ \\
\hline \multirow{2}{*}{$\begin{array}{l}\text { Obesity vs. normal } \\
\text { and thin }\end{array}$} & $\leq 23.9$ & 212 & 57 & 155 & \multirow[t]{2}{*}{0.690} & \multirow[t]{2}{*}{0.406} & \multirow[t]{2}{*}{0.695} & \multirow[t]{2}{*}{$0.293-1.647$} \\
\hline & $27-29.9$ & 26 & 9 & 17 & & & & \\
\hline $\begin{array}{l}\text { Severe obesity vs. } \\
\text { normal and thin }\end{array}$ & $\geq 30$ & 9 & 2 & 7 & 0.096 & 0.757 & 1.287 & $0.260-6.379$ \\
\hline
\end{tabular}

BMI, body mass index.

Table 8 Comparison of treatment in 3 overweight groups

\begin{tabular}{|c|c|c|c|c|c|c|}
\hline Treatment & Total $(n=103)$ & $24-26.9(n=68)$ & $27-29.9(n=26)$ & $\geq 30(n=9)$ & Chi-square value & $P$ value \\
\hline Mastectomy & 95 & 61 & 25 & 9 & 1.922 & 0.383 \\
\hline Breast-conserving surgery & 8 & 7 & 1 & 0 & & \\
\hline \multicolumn{7}{|l|}{ Chemotherapy } \\
\hline No & 9 & 3 & 5 & 1 & & \\
\hline \multicolumn{7}{|l|}{ Chemotherapy regimens } \\
\hline Anthracycline + taxane & 46 & 34 & 10 & 2 & 3.022 & 0.216 \\
\hline Other & 57 & 34 & 16 & 7 & & \\
\hline
\end{tabular}

B, BMI was positively correlated with age. Luminal A and B represent hormone receptor-positive breast cancer patients. Therefore, we believe that the increase in BMI observed in these groups may be related to changes in hormone levels. It has been reported that women's weight increases mainly due to age. After menopause, the free androgen index increases, and the level of sex hormone-binding globulin decreases, both phenomena likely causing a gradual increase in patients' BMI $(38,39)$. This explanation is consistent with the conclusions reached in this study.

When we studied the relationship between BMI and prognosis, we found that there was no statistically significant relationship between $\mathrm{BMI}$ and DFS $(\mathrm{P}=0.5275)$ or OS $(\mathrm{P}=0.4493)$. In one-to-one subgroup comparisons, no statistically significant differences were discovered. Studies in Europe and America (22), and in other Asian countries $(26,27)$, have reached different conclusions from ours, which may be due to differences in the genetic backgrounds of the studied populations. The European and American populations are mainly composed of Caucasians, while the Japanese population is mainly composed of $\mathrm{He}$ ethnic groups, and the Korean population of Korean ethnic groups. The patients enrolled in this study were mainly from the Yunnan and Guangxi provinces in southern China. Yunnan and Guangxi are the largest ethnic minorities in China. Therefore, these ethnic differences may lead to different research results. Different results may also emerge due to different lifestyles, including differences in physical labor intensity and nutrition intake. Most of the obesity in the European and American population is caused by longterm sedentariness and high-fat diets (40). On the contrary, most patients included in this study were farmers, whose 
diets mainly consist of coarse grains and whose relatively short height and overweight may originate from long-term labor. This may also be a reason why the prognoses of the three groups of under- $160 \mathrm{~cm}$ height/overweight patients did not differ significantly in this article.

After studying the relationship between BMI and prognosis, we performed a subgroup analysis and found that within the different groups of molecular type of breast cancer, the BMI was not related to the number of recurrences. This conclusion is consistent with the results found earlier in this study. We then classified the recurrences according to the organ affected by the metastasis and found that the lung is the organ with the highest rate of singleorgan metastasis. However, the recurrence rate of metastases affecting all organs except the lung, bone, liver, and brain is higher. $\mathrm{Wu}$ and Ording reported that patients with breast cancer are most likely to have bone metastases, followed by lung metastases $(41,42)$. Because the patients enrolled in this study were mainly from southern China, our conclusions should have implications for the future treatment of the southern Chinese population.

After finding that the BMI had no relationship with prognosis, we formed 5 groups of patients according to weight to investigate a possible range of weights associated with higher recurrence of cancer. In all groups, there were fewer patients with recurrence than without recurrence $(\mathrm{P}=0.525)$. None of the comparisons between the different groups revealed statistically significant differences. Therefore, we believe that weight does not play a role in the recurrence of breast cancer.

We divided patients with BMI over 24 into three groups and compared the treatments received by patients from these three overweight groups. We did not find significant differences in surgical treatment, chemotherapy, or endocrine therapy among these three groups. We think the reason for this result is that the choice of treatment methods for patients is based on breast cancer CSCO guidelines (43) and breast cancer NCCN guidelines (44), independent of the BMI. Patients with different BMI have no obvious differences in prognosis after receiving the same treatment plan. Therefore, the protocol in the guidelines is applicable to all patients with different BMI, and the prognosis of patients with different BMI after receiving the same treatment is not significantly different.

The limitation of this study is that we only performed prognostic analysis on a relatively small number of patients. Using a larger cohort would better assess the impact of BMI on the prognosis of breast cancer patients. In the context of current precision medicine, the expression of different genes can predict the prognosis of breast cancer patients. Although we grouped the enrolled patients to reduce the impact of differential expression of proto-oncogenes and tumor suppressor genes on prognosis, under the same BMI conditions the molecular characteristics of the cancer types may still interfere. The impact of BMI on prognosis may be weakened by these molecular characteristics.

\section{Conclusions}

In summary, we found that BMI is related to age and is not related to the prognosis of breast cancer. We did not identify a weight threshold beyond which the risk of recurrence is increased. In our retrospective analysis, we found that the BMI of the Chinese population is not related to the prognosis of breast cancer.

\section{Acknowledgments}

Funding: The present study was supported by the National Natural Science Foundation of China (grant no. 81960542 and 81960517), Science and Technology Project of Yunnan Provincial Science and Technology Department (grant no. 202001AU070053 and 202001AU070093), Scientific Research Foundation of Yunnan Education Department (grant no. 2019J1288 and 2020J0198).

\section{Footnote}

Reporting Checklist: The authors have completed the STROBE reporting checklist. Available at http://dx.doi. org/10.21037/gs-20-488

Data Sharing Statement: Available at http://dx.doi. org/10.21037/gs-20-488

Conflicts of Interest: All authors have completed the ICMJE uniform disclosure form (available at http://dx.doi. org/10.21037/gs-20-488). The authors have no conflicts of interest to declare.

Ethical Statement: The authors are accountable for all aspects of the work in ensuring that questions related to the accuracy or integrity of any part of the work are appropriately investigated and resolved. The study was conducted in accordance with the Declaration of Helsinki (as revised in 2013). The study was approved by People's 
committee of the Third Affiliated Hospital of Kunming Medical University (No. QT202001), the Affiliated Tumor Hospital of Guangxi Medical University (No. LW2020058), and the First Affiliated Hospital of Xinxiang Medical University (No. 2020341) and informed consent was taken from all the patients.

Open Access Statement: This is an Open Access article distributed in accordance with the Creative Commons Attribution-NonCommercial-NoDerivs 4.0 International License (CC BY-NC-ND 4.0), which permits the noncommercial replication and distribution of the article with the strict proviso that no changes or edits are made and the original work is properly cited (including links to both the formal publication through the relevant DOI and the license). See: https://creativecommons.org/licenses/by-nc-nd/4.0/.

\section{References}

1. Ferlay J, Colombet M, Soerjomataram I, et al. Estimating the global cancer incidence and mortality in 2018: GLOBOCAN sources and methods. Int J Cancer 2019;144:1941-53.

2. Siegel RL, Miller KD, Jemal A. Cancer statistics, 2016. CA Cancer J Clin 2016;66:7-30.

3. Kohler BA, Sherman RL, Howlader N, et al. Annual Report to the Nation on the Status of Cancer, 1975 2011, Featuring Incidence of Breast Cancer Subtypes by Race/Ethnicity, Poverty, and State. J Natl Cancer Inst 2015;107:djv048.

4. Johnston MP, Patel J, Byrne CD. Causes of Mortality in Non-Alcoholic Fatty Liver Disease (NAFLD) and Alcohol Related Fatty Liver Disease (AFLD). Curr Pharm Des 2020;26:1079-92.

5. Ardahan M, Konal E. The prevalence of hypertension and obesity and effective factors: A cross-sectional bazaar study. J Pak Med Assoc 2019;69:1018-21.

6. Spurr S, Bally J, Bullin C, et al. The prevalence of undiagnosed Prediabetes/type 2 diabetes, prehypertension/ hypertension and obesity among ethnic groups of adolescents in Western Canada. BMC Pediatr 2020;20:31.

7. Wang Y, Li Y, Liu X, et al. Prevalence and Influencing Factors of Coronary Heart Disease and Stroke in Chinese Rural Adults: The Henan Rural Cohort Study. Front Public Health 2020;7:411.

8. Jakab AE, Hidvégi EV, Illyés M, et al. [Prevalence of hypertension in overweight and obese Hungarian children and adolescents]. Orv Hetil 2020;161:151-60.
9. Piotrowicz K, Gąsowski J. Risk Factors for Frailty and Cardiovascular Diseases: Are They the Same. Adv Exp Med Biol 2020;1216:39-50.

10. Chen Z, Li SN, Wang X, et al. [The incidence of hypertension, overweight, and obesity and relationship with cardiovascular events among middle-aged Chinese: 6 years follow-up results]. Zhonghua Xin Xue Guan Bing Za Zhi 2020;48:47-53.

11. Liu MC, Gardner AB, Wolford JE, et al. Endometrial cancer in the morbidly obese: a review. Curr Opin Obstet Gynecol 2020;32:42-50.

12. Bao C, Yang R, Pedersen NL, et al. Overweight in midlife and risk of cancer in late life: A nationwide Swedish twin study. Int J Cancer 2019;144:2128-34.

13. PROFESSOR H. G. GREENISH. Br Med J 1933;2:318.

14. Zhu CY, Qu JC, Cao HX, et al. Obesity and nonalcoholic fatty liver disease associated with adenocarcinoma in patients with lung cancer. Medicine (Baltimore) 2019;98:e17098.

15. Schlesinger S, Siegert S, Koch M, et al. Postdiagnosis body mass index and risk of mortality in colorectal cancer survivors: a prospective study and meta-analysis. Cancer Causes Control 2014;25:1407-18.

16. Neuhouser ML, Aragaki AK, Prentice RL, et al. Overweight, Obesity, and Postmenopausal Invasive Breast Cancer Risk: A Secondary Analysis of the Women's Health Initiative Randomized Clinical Trials. JAMA Oncol 2015;1:611-21.

17. Keum N, Greenwood DC, Lee DH, et al. Adult weight gain and adiposity-related cancers: a dose-response metaanalysis of prospective observational studies. J Natl Cancer Inst 2015;107:dju428.

18. White AJ, Nichols HB, Bradshaw PT, et al. Overall and central adiposity and breast cancer risk in the Sister Study. Cancer 2015;121:3700-8.

19. Moore AH, Trentham-Dietz A, Burns M, et al. Obesity and mortality after locoregional breast cancer diagnosis. Breast Cancer Res Treat 2018;172:647-57.

20. Berclaz G, Li S, Price KN, et al. Body mass index as a prognostic feature in operable breast cancer: the International Breast Cancer Study Group experience. Ann Oncol 2004;15:875-84.

21. Fontanella C, Lederer B, Gade S, et al. Impact of body mass index on neoadjuvant treatment outcome: a pooled analysis of eight prospective neoadjuvant breast cancer trials. Breast Cancer Res Treat 2015;150:127-39.

22. Chan DS, Vieira AR, Aune D, et al. Body mass index and survival in women with breast cancer-systematic literature 
review and meta-analysis of 82 follow-up studies. Ann Oncol 2014;25:1901-14.

23. Vernaci G, Dieci MV, Manfrin S, et al. BMI is an independent prognostic factor for late outcome in patients diagnosed with early breast cancer: A landmark survival analysis. Breast 2019;47:77-84.

24. Sun L, Zhu Y, Qian Q, et al. Body mass index and prognosis of breast cancer: An analysis by menstruation status when breast cancer diagnosis. Medicine (Baltimore) 2018;97:e11220.

25. Kawai M, Minami Y, Nishino Y, et al. Body mass index and survival after breast cancer diagnosis in Japanese women. BMC Cancer 2012;12:149.

26. Kawai M, Tomotaki A, Miyata H, et al. Body mass index and survival after diagnosis of invasive breast cancer: a study based on the Japanese National Clinical DatabaseBreast Cancer Registry. Cancer Med 2016;5:1328-40.

27. Jeong SH, An Y, Ahn C, et al. Body mass index and risk of breast cancer molecular subtypes in Korean women: a casecontrol study. Breast Cancer Res Treat 2020;179:459-70.

28. Wang K, Wu YT, Zhang X, et al. Clinicopathologic and Prognostic Significance of Body Mass Index (BMI) among Breast Cancer Patients in Western China: A Retrospective Multicenter Cohort Based on Western China Clinical Cooperation Group (WCCCG). Biomed Res Int 2019;2019:3692093.

29. Cao S, Zhou J, Zhu Z, et al. Adult weight change and the risk of pre- and postmenopausal breast cancer in the Chinese Wuxi Exposure and Breast Cancer Study. Breast Cancer Res Treat 2019;173:647-55.

30. WHO Expert Consultation. Appropriate body-mass index for Asian populations and its implications for policy and intervention strategies. Lancet 2004;363:157-63.

31. Solomon JP, Dell'Aquila M, Fadare O, et al. Her2/ neu Status Determination in Breast Cancer: A Single Institutional Experience Using a Dual-Testing Approach With Immunohistochemistry and Fluorescence In Situ Hybridization. Am J Clin Pathol 2017;147:432-7.

32. Goldhirsch A, Winer EP, Coates AS, et al. Personalizing the treatment of women with early breast cancer: highlights of the St Gallen International Expert Consensus on the Primary Therapy of Early Breast Cancer 2013. Ann Oncol 2013;24:2206-23.

33. Tang S, Zhang Q, Tang X, et al. Long-term comparisons of the efficacy, safety, and pregnancy outcomes of adjuvant tamoxifen plus ovarian function suppression in premenopausal Han and Zhuang Chinese patients with hormone receptor-positive early breast cancer. J Int Med
Res 2019;47:641-52.

34. Ligibel JA, Alfano CM, Courneya KS, et al. American Society of Clinical Oncology position statement on obesity and cancer. J Clin Oncol 2014;32:3568-74.

35. Gama RR, Song Y, Zhang Q, et al. Body mass index and prognosis in patients with head and neck cancer. Head Neck 2017;39:1226-33.

36. Iyengar NM, Chen IC, Zhou XK, et al. Adiposity, Inflammation, and Breast Cancer Pathogenesis in Asian Women. Cancer Prev Res (Phila) 2018;11:227-36.

37. Bielawski K, Rhone P, Bulsa M, et al. Pre-Operative Combination of Normal BMI with Elevated YKL-40 and Leptin but Lower Adiponectin Level Is Linked to a Higher Risk of Breast Cancer Relapse: A Report of FourYear Follow-Up Study. J Clin Med 2020;9:1742.

38. Sternfeld B, Wang H, Quesenberry CP Jr, et al. Physical activity and changes in weight and waist circumference in midlife women: findings from the Study of Women's Health Across the Nation. Am J Epidemiol 2004;160:912-22.

39. Sutton-Tyrrell K, Zhao X, Santoro N, et al. Reproductive hormones and obesity: 9 years of observation from the Study of Women's Health Across the Nation. Am J Epidemiol 2010;171:1203-13.

40. Blümel JE, Fica J, Chedraui P, et al. Sedentary lifestyle in middle-aged women is associated with severe menopausal symptoms and obesity. Menopause 2016;23:488-93.

41. Wu Q, Li J, Zhu S, et al. Breast cancer subtypes predict the preferential site of distant metastases: a SEER based study. Oncotarget 2017;8:27990-6.

42. Ording AG, Heide-Jørgensen U, Christiansen CF, et al. Site of metastasis and breast cancer mortality: a Danish nationwide registry-based cohort study. Clin Exp Metastasis 2017;34:93-101.

43. Huang X, Yin YM. [Updates of Chinese Society of Clinical Oncology (CSCO) guideline for breast cancer in 2018]. Zhonghua Yi Xue Za Zhi 2018;98:1213-7.

44. Telli ML, Gradishar WJ, Ward JH. NCCN Guidelines Updates: Breast Cancer. J Natl Compr Canc Netw 2019;17:552-5.

Cite this article as: Tan X, Huang D, Zhang F, Zhao Y, Tan M, Li H, Zhang H, Wang K, Li H, Liu D, Guo R, Tang S. Evaluation of the body mass index in breast cancer prognosis in a cohort of small-stature overweight patients: multi-center study in China. Gland Surg 2021;10(1):23-34. doi: 10.21037/ gs-20-488 
Supplementary

Table S1 Comparison of clinicopathological characteristics between 5 different BMI group in luminal A patients

\begin{tabular}{|c|c|c|c|c|c|c|c|}
\hline Variables & Total $(n=49)$ & $<18.5(\mathrm{n}=6)$ & $\begin{array}{c}18.5-23.9 \\
(n=26)\end{array}$ & $\begin{array}{c}24-26.9 \\
(n=10)\end{array}$ & $27-29.9(n=5)$ & $\geq 30(n=2)$ & $P$ value \\
\hline \multicolumn{8}{|c|}{ Age (years) } \\
\hline$<50$ & 30 & 6 & 17 & 7 & 0 & 0 & 0.002 \\
\hline$\geq 50$ & 19 & 0 & 9 & 3 & 5 & 2 & \\
\hline \multicolumn{8}{|c|}{ Tumor size } \\
\hline$\leq 2 \mathrm{~cm}$ & 14 & 2 & 7 & 4 & 0 & 1 & 0.632 \\
\hline $2-5 \mathrm{~cm}$ & 33 & 4 & 18 & 5 & 5 & 1 & \\
\hline$>5 \mathrm{~cm}$ & 2 & 0 & 1 & 1 & 0 & 0 & \\
\hline \multicolumn{8}{|c|}{ Lymph nodes status } \\
\hline- & 25 & 2 & 15 & 5 & 2 & 1 & 0.833 \\
\hline+ & 24 & 4 & 11 & 5 & 3 & 1 & \\
\hline
\end{tabular}

BMI, body mass index.

Table S2 Comparison of clinicopathological characteristics between 5 different BMI group in Luminal B patients

\begin{tabular}{|c|c|c|c|c|c|c|c|}
\hline Variables & Total $(n=171)$ & $<18.5(n=10)$ & $\begin{array}{c}18.5-23.9 \\
(n=110)\end{array}$ & $\begin{array}{c}24-26.9 \\
(n=32)\end{array}$ & $\begin{array}{c}27-29.9 \\
(n=14)\end{array}$ & $\geq 30(n=5)$ & $P$ value \\
\hline \multicolumn{8}{|c|}{ Age (years) } \\
\hline$<50$ & 113 & 5 & 83 & 16 & 7 & 2 & 0.010 \\
\hline$\geq 50$ & 58 & 5 & 27 & 16 & 7 & 3 & \\
\hline \multicolumn{8}{|c|}{ Tumor size } \\
\hline$\leq 2 \mathrm{~cm}$ & 31 & 2 & 19 & 8 & 2 & 0 & 0.566 \\
\hline $2-5 \mathrm{~cm}$ & 127 & 6 & 82 & 22 & 12 & 5 & \\
\hline$>5 \mathrm{~cm}$ & 13 & 2 & 9 & 2 & 0 & 0 & \\
\hline \multicolumn{8}{|c|}{ Lymph nodes status } \\
\hline- & 75 & 4 & 46 & 16 & 7 & 2 & 0.916 \\
\hline+ & 96 & 6 & 64 & 16 & 7 & 3 & \\
\hline
\end{tabular}

BMI, body mass index.

Table S3 Comparison of clinicopathological characteristics between 5 different BMI group in HER2 patients

\begin{tabular}{|c|c|c|c|c|c|c|c|}
\hline Variables & Total $(n=51)$ & $<18.5(\mathrm{n}=2)$ & $\begin{array}{c}18.5-23.9 \\
(n=33)\end{array}$ & $\begin{array}{c}24-26.9 \\
(n=13)\end{array}$ & $27-29.9(n=2)$ & $\geq 30(n=1)$ & $\mathrm{P}$ value \\
\hline \multicolumn{8}{|c|}{ Age (years) } \\
\hline$<50$ & 25 & 0 & 19 & 6 & 0 & 0 & 0.193 \\
\hline$\geq 50$ & 26 & 2 & 14 & 7 & 2 & 1 & \\
\hline \multicolumn{8}{|c|}{ Tumor size } \\
\hline$\leq 2 \mathrm{~cm}$ & 6 & 0 & 5 & 1 & 0 & 0 & 0.337 \\
\hline $2-5 \mathrm{~cm}$ & 36 & 2 & 20 & 12 & 1 & 1 & \\
\hline$>5 \mathrm{~cm}$ & 9 & 0 & 8 & 0 & 1 & 0 & \\
\hline \multicolumn{8}{|c|}{ Lymph nodes status } \\
\hline- & 25 & 1 & 19 & 5 & 0 & 0 & 0.406 \\
\hline+ & 26 & 1 & 14 & 8 & 2 & 1 & \\
\hline
\end{tabular}

BMI, body mass index; HER2, human epidermal growth factor receptor-2.

Table S4 Comparison of clinicopathological characteristics between 5 different BMI group in TNBC patients

\begin{tabular}{|c|c|c|c|c|c|c|c|}
\hline Variables & Total $(n=44)$ & $<18.5(n=1)$ & $\begin{array}{c}18.5-23.9 \\
(n=24)\end{array}$ & $\begin{array}{c}24-26.9 \\
(n=13)\end{array}$ & $27-29.9(n=5)$ & $\geq 30(n=1)$ & $P$ value \\
\hline \multicolumn{8}{|c|}{ Age (years) } \\
\hline$<50$ & 28 & 1 & 17 & 6 & 4 & 0 & 0.286 \\
\hline$\geq 50$ & 16 & 0 & 7 & 7 & 1 & 1 & \\
\hline \multicolumn{8}{|c|}{ Tumor size } \\
\hline$\leq 2 \mathrm{~cm}$ & 8 & 1 & 3 & 3 & 0 & 1 & 0.240 \\
\hline $2-5 \mathrm{~cm}$ & 31 & 0 & 18 & 9 & 4 & 0 & \\
\hline$>5 \mathrm{~cm}$ & 5 & 0 & 3 & 1 & 1 & 0 & \\
\hline \multicolumn{8}{|c|}{ Lymph nodes status } \\
\hline- & 22 & 1 & 13 & 7 & 1 & 0 & 0.454 \\
\hline+ & 22 & 0 & 11 & 6 & 4 & 1 & \\
\hline
\end{tabular}

$\mathrm{BMI}$, body mass index; TNBC, triple negative breast cancer. 